\title{
Magnetic Search Coil (MSC) of Plasma Wave Experiment (PWE) aboard the Arase (ERG) satellite
}

\author{
Mitsunori Ozaki ${ }^{*}{ }^{*}$, Satoshi Yagitani ${ }^{1}$, Yoshiya Kasahara ${ }^{1}$, Hirotsugu Kojima ${ }^{2}$, Yasumasa Kasaba ${ }^{3}$, \\ Atsushi Kumamoto ${ }^{3}$, Fuminori Tsuchiya ${ }^{3}$, Shoya Matsuda ${ }^{4}$, Ayako Matsuoka ${ }^{5}$, Takashi Sasaki ${ }^{6}$ \\ and Takahiro Yumoto ${ }^{6}$
}

\begin{abstract}
This paper presents detailed performance values of the Magnetic Search Coil (MSC) that is part of the Plasma Wave Experiment on board the Arase (ERG) satellite. The MSC consists of a three-axis search coil magnetometer with a 200-mm-long magnetic core. The MSC plays a central role in the magnetic field observations, particularly for whistler mode chorus and hiss waves in a few $\mathrm{kHz}$ frequency range, which may cause local acceleration and/or rapid loss of radiation belt electrons. Accordingly, the MSC was carefully designed and developed to operate well in harsh radiation environments. To ascertain the wave-normal vectors, polarizations, and refractive indices of the plasma waves in a wide frequency band, the output signals detected by the MSC are fed into the two different wave receivers: one is the WaveForm Capture/Onboard Frequency Analyzer for waveform and spectrum observations in the frequency range from a few $\mathrm{Hz}$ up to $20 \mathrm{kHz}$, and the other is the High Frequency Analyzer for spectrum observations in the frequency range from 10 to $100 \mathrm{kHz}$. The noise equivalent magnetic induction of the MSC is $20 \mathrm{fT} / \mathrm{Hz}^{1 / 2}$ at a frequency of $2 \mathrm{kHz}$, and the null depth of directionality is $-40 \mathrm{~dB}$, which is equivalent to an angular error less than $1^{\circ}$. The MSC on board the Arase satellite is the first experiment using a current-sensitive preamplifier for probing the plasma waves in the radiation belts.
\end{abstract}

Keywords: Search coil magnetometer, Arase (ERG) satellite, Plasma waves, Radiation belts, Geospace

\section{Introduction}

Important role of plasma waves in radiation belt dynamics The radiation belts surrounding the Earth contain enhanced relativistic particles (Baker et al. 1986; Reeves et al. 2003; Miyoshi and Kataoka 2005; Shprits et al. 2013). The inner radiation belt ( $L \approx 1$ to 3 ) is dominated by relativistic protons, while the outer belt $(L \approx 4$ to 6$)$ consists of relativistic electrons trapped in the geomagnetic fields. A third belt is found between geomagnetic storms (Baker et al. 2013). Although the acceleration and loss mechanisms of the radiation belts are still open questions, it has been established that plasma waves fulfill a

\footnotetext{
*Correspondence: ozaki@is.t.kanazawa-u.ac.jp

${ }^{1}$ Graduate School of Natural Science and Technology, Kanazawa

University, Kakuma-machi, Kanazawa 920-1192, Japan

Full list of author information is available at the end of the article
}

crucial role in both processes (Schulz and Lanzerotti 1974; Summers et al. 1998; Thorne 2010). Two major mechanisms have been presented: one is inward and outward radial diffusion via ultralow-frequency (ULF) waves (e.g., Schulz and Lanzerotti 1974; Elkington et al. 1999; Hudson et al. 2000; Shprits et al. 2008), and the other is local acceleration and loss processes via wave-particle interactions (e.g., Summers et al. 1998; Thorne 2010; Thorne et al. 2013). It is particularly noteworthy that the Van Allen Probes have observed local electron acceleration during a geomagnetic storm (Reeves et al. 2013), which tends to support the importance of wave-particle interactions.

Chorus waves contribute to the local acceleration and loss of relativistic electrons in the outer belt via waveparticle interactions (Horne and Thorne 2003; Katoh and 
Omura 2007; Kasahara et al. 2009; Thorne et al. 2013). Chorus waves in the extremely low frequency (ELF) and very low frequency (VLF) bands are the most common whistler mode waves in the inner magnetosphere (Burtis and Helliwell 1969; Tsurutani and Smith 1974). Chorus waves have a frequency range between about $0.1 f_{\text {ceq }}$ and $0.7 f_{\text {ceq }}$, where $f_{\text {ceq }}$ is the equatorial electron gyrofrequency. Additionally, chorus waves usually have a frequency gap at half the equatorial electron gyrofrequency and are classified into lower $\left(0.1 f_{\text {ceq }}\right.$ to $\left.0.5 f_{\text {ceq }}\right)$ and upper $\left(0.5 f_{\text {ceq }}\right.$ to $\left.0.7 f_{\text {ceq }}\right)$ bands below and above the gap (Santolík et al. 2003). The gap can be caused by a nonlinear damping process (Yagitani et al. 2014). Hiss waves in the ELF band are also important for loss of relativistic electrons (Summers et al. 2008). Magnetosonic waves (sometimes referred to as equatorial noises) below the lower hybrid frequency can also contribute to local acceleration via wave-particle interactions (e.g., Horne et al. 2007). Electromagnetic ion cyclotron (EMIC) waves below the proton gyrofrequency (Jacobs et al. 1964; Fukunishi et al. 1981; Pickett et al. 2010) can contribute to loss of relativistic electrons, due to strong pitch angle scattering (Rodger et al. 2008; Jordanova et al. 2008; Miyoshi et al. 2008; Omura and Zhao 2012). These plasma waves are major candidates in the rapid local acceleration and loss processes of relativistic electrons in the radiation belts.

\section{Brief overview of search coil magnetometers}

From the dawn of space exploration to present, search coil magnetometers have contributed to understanding of the radiation belts, magnetospheric dynamics, and planetary science. The specifications of the search coil magnetometers on board the Arase satellite, which is formerly known as the Exploration of energization and Radiation in Geospace (ERG) mission, and other major satellites are listed in Table 1. Because of their high robustness under harsh (temperature and radiation) environments, search coil magnetometers have been widely used in space for over a half century, and ongoing research efforts have resulted in new techniques for achieving wider bandwidth, increased miniaturization, and improved noise equivalent magnetic induction (NEMI) values. To achieve a wider bandwidth, a new sensor that can simultaneously monitor two (a few $\mathrm{kHz}$ and $100 \mathrm{kHz}$ ) different resonant frequencies was proposed (Coillot et al. 2010; Ozaki et al. 2013). Miniaturization of sensors on board the Mercury Magnetospheric Orbiter (MMO) and the Magnetospheric Multiscale (MMS) satellites has been realized using magnetic concentrators (Coillot et al. 2010; Le Contel et al. 2016), while maintaining a reasonable NEMI value. Drastic miniaturization of preamplifiers has been achieved by using application-specific integrated circuit (ASIC) technology (Rhouni et al. 2013; Ozaki et al. 2014, 2016).

This paper focuses, in particular, on the Magnetic Search Coil (MSC) of the Plasma Wave Experiment (PWE) (Kasahara et al. 2018) on board the Arase satellite (Miyoshi et al. 2012), which plays a central role in the plasma wave observations of magnetic field vectors in the frequency range between a few $\mathrm{Hz}$ to $100 \mathrm{kHz}$. The MSC consists of a three-axis search coil magnetometer with a 200-mm-long magnetic core. The MSC can provide accurate waveform data (amplitude and phase) of magnetic field components because of its robustness even in plasma and radiation environments. Because accurate phase measurements of plasma waves are essential for the analysis of wave-particle interaction processes (Fukuhara et al. 2009; Katoh et al. 2018), the MSC was designed especially for magnetic field observations of chorus, hiss, and magnetosonic waves in the frequency range from a few $\mathrm{Hz}$ to $100 \mathrm{kHz}$, while a fluxgate magnetometer, hereafter referred to as MGF (Matsuoka et al. 2018), is used for ULF and EMIC wave observations below a frequency of $10 \mathrm{~Hz}$. Design and manufacturing for the MSC were mainly performed by Kanazawa University and NIPPI Corporation, both of which were deeply involved in developments of search coil magnetometers on board the GEOTAIL (Matsumoto et al. 1994) and the MMO (Kasaba et al. 2010) satellites. Since the mission objective of the Arase satellite is to directly observe the heart of the Earth's radiation belts, the MSC was developed specifically for use in harsh radiation environments.

\section{MSC description}

\section{Arase satellite overview}

In order to understand the dynamics of Earth's radiation belts, satellite and ground-based observations along with simulation studies are conducted (Miyoshi et al. 2012; Shiokawa 2017). As part of this effort, the Arase satellite, which is equipped with particle instruments that cover a wide energy range ( $10 \mathrm{eV}$ to $20 \mathrm{MeV}$ for electrons and $10 \mathrm{eV}$ to $180 \mathrm{keV}$ for ions), a DC magnetometer, and plasma wave receivers for a wide frequency range (a few $\mathrm{Hz}$ to $10 \mathrm{MHz}$ ), was launched on December 20, 2016. Information on wave-normal vectors, polarizations, and refractive indices of the plasma waves is obtained by the PWE on board the Arase satellite. The MSC belonging to the PWE is composed of a triaxial sensor (referred to as MSC-S), low-noise preamplifiers (addressed as MSC-PA), and a 5-m-long extendable mast (addressed as MAST).

Figures 1 and 2 show the spinning satellite geometry axis (SGA) coordinates represented by the symbols $(X, Y, Z)$ and the configuration of the MSC in the $\alpha \beta \gamma$ coordinates, respectively. To mitigate the magnetic noise coming from the drive signals of the MGF, the MSC-S 
Table 1 Major examples of spaceborne search coil magnetometers for plasma wave measurements

\begin{tabular}{|c|c|c|c|c|}
\hline Satellite & Launch year & Core length $(\mathrm{m})$ & Frequency range & NEMI \\
\hline OGO-I-VI (Frandsen et al. 1969) & 1964-1969 & 0.27 & $0.01 \mathrm{~Hz}$ to $1 \mathrm{kHz}$ & $\leq 100 \mathrm{fT} / \mathrm{Hz}^{1 / 2}$ at 50 to $1000 \mathrm{~Hz}$ \\
\hline IMP-8 (Gurnett et al. 1976) & 1973 & 0.46 & $40 \mathrm{~Hz}$ to $1.78 \mathrm{kHz}$ & $10 \mathrm{fT} / \mathrm{Hz}^{1 / 2}$ at $1 \mathrm{kHz}$ \\
\hline GEOS 1 and 2 (S-300 Experimenters 1979) & 1977 and 1978 & $?$ & 0.1 to $450 \mathrm{~Hz}$ & $0.1 \mathrm{pT} / \mathrm{Hz}^{1 / 2}$ at $30 \mathrm{~Hz}$ \\
\hline GEOS 1 and 2 (S-300 Experimenters 1979) & 1977 and 1978 & $?$ & 0.45 to $20 \mathrm{kHz}$ & $3 \mathrm{fT} / \mathrm{Hz}^{1 / 2}$ at $5 \mathrm{kHz}$ \\
\hline ISEE-3 (Scarf et al. 1978) & 1978 & 0.4 & $17 \mathrm{~Hz}$ to $100 \mathrm{kHz}$ & $20 \mathrm{fT} / \mathrm{Hz}^{1 / 2}$ at $200 \mathrm{~Hz}$ \\
\hline DE-1 and DE-2 (Shawhan et al. 1981) & 1981 & 0.4 & $1 \mathrm{~Hz}$ to $1 \mathrm{kHz}$ & $0.1 \gamma-\mathrm{Hz}<35 \mathrm{kHz}$ \\
\hline Akebono (Fukunishi et al. 1990) & 1989 & 0.3 & 1 to $800 \mathrm{~Hz}$ & $0.3 \mathrm{pT}$ at $10 \mathrm{~Hz}$ \\
\hline Galileo (Gurnett et al. 1992) & 1989 & 0.26 & $5 \mathrm{~Hz}$ to $3.5 \mathrm{kHz}$ & $50 \mathrm{fT} / \mathrm{Hz}^{1 / 2}$ at $100 \mathrm{~Hz}$ \\
\hline Galileo (Gurnett et al. 1992) & 1989 & 0.28 & 1 to $50 \mathrm{kHz}$ & $3 \mathrm{fT} / \mathrm{Hz}^{1 / 2}$ at $20 \mathrm{kHz}$ \\
\hline CRRES (Anderson et al. 1992) & 1990 & 0.4 & $5.6 \mathrm{~Hz}$ to $400 \mathrm{kHz}$ & $35 \mu \mathrm{V} / \mathrm{nT} \mathrm{Hz}$ up to $10 \mathrm{kHz}$ \\
\hline GEOTAIL (Matsumoto et al. 1994) & 1992 & 0.3 & $10 \mathrm{~Hz}$ to $12 \mathrm{kHz}$ & $20 \mathrm{fT} / \mathrm{Hz}^{1 / 2}$ at $100 \mathrm{~Hz}$ \\
\hline Freja (Holback et al. 1994) & 1992 & 0.27 & $30 \mathrm{~Hz}$ to $16 \mathrm{kHz}$ & $10 \mathrm{fT} / \mathrm{Hz}^{1 / 2}$ \\
\hline WIND (Bougeret et al. 1995) & 1994 & 0.4 & A few $\mathrm{Hz}$ to $3 \mathrm{kHz}$ & $10 \mathrm{fT} / \mathrm{Hz}^{1 / 2}$ at $1 \mathrm{kHz}$ \\
\hline Magion 4 (Blęki et al. 1997) & 1995 & $?$ & $1 \mathrm{~Hz}$ to $2 \mathrm{kHz}$ & $30 \mathrm{fT} / \mathrm{Hz}^{1 / 2}$ at $100 \mathrm{~Hz}$ \\
\hline Polar (Gurnett et al. 1995) & 1996 & 0.4 & $0.1 \mathrm{~Hz}$ to $50 \mathrm{kHz}$ & $10 \mathrm{fT} / \mathrm{Hz}^{1 / 2}$ at $1 \mathrm{kHz}$ \\
\hline FAST (Elphic et al. 2001) & 1996 & 0.18 & $10 \mathrm{~Hz}$ to $16 \mathrm{kHz}$ & $3 \mathrm{fT} / \mathrm{bit}^{-1}$ at $16 \mathrm{kHz}$ \\
\hline FAST (Elphic et al. 2001) & 1996 & 0.53 & $10 \mathrm{~Hz}$ to $1 \mathrm{MHz}$ & $3 \mathrm{fT} / \mathrm{bit}^{-1}$ at $16 \mathrm{kHz}$ \\
\hline Interball 2 (Lefeuvre et al. 1998) & 1996 & $?$ & $0.01 \mathrm{~Hz}$ to $1 \mathrm{kHz}$ & $8 \mathrm{fT} / \mathrm{Hz}^{1 / 2}$ at $400 \mathrm{~Hz}$ \\
\hline Interball 2 (Lefeuvre et al. 1998) & 1996 & $?$ & 1 to $20 \mathrm{kHz}$ & $?$ \\
\hline Interball 2 (Lefeuvre et al. 1998) & 1996 & $?$ & $40 \mathrm{kHz}$ to $2 \mathrm{MHz}$ & $3 \mathrm{fT} / \mathrm{Hz}^{1 / 2}$ at $100 \mathrm{kHz}$ \\
\hline Cassini (Gurnett et al. 2004) & 1997 & 0.25 & $1 \mathrm{~Hz}$ to $20 \mathrm{kHz}$ & $20 \mathrm{fT} / \mathrm{Hz}^{1 / 2}$ at $1 \mathrm{kHz}$ \\
\hline Cluster II (Cornilleau-Wehrlin et al. 2003) & 2000 & 0.27 & $0.1 \mathrm{~Hz}$ to $4 \mathrm{kHz}$ & $10 \mathrm{fT} / \mathrm{Hz}^{1 / 2}$ at $1 \mathrm{kHz}$ \\
\hline DEMETER (Séran and Fergeau 2005) & 2004 & 0.17 & A few $\mathrm{Hz}$ to $20 \mathrm{kHz}$ & $4 \mathrm{fT} / \mathrm{Hz} \mathrm{z}^{1 / 2}$ at $6 \mathrm{kHz}$ \\
\hline THEMIS (Roux et al. 2008) & 2007 & 0.17 & $0.1 \mathrm{~Hz}$ to $4 \mathrm{kHz}$ & $20 \mathrm{fT} / \mathrm{Hz}^{1 / 2}$ at $1 \mathrm{kHz}$ \\
\hline Van Allen Probes (Kletzing et al. 2013) & 2012 & 0.4 & $10 \mathrm{~Hz}$ to $12 \mathrm{kHz}$ & $5 \mathrm{fT} / \mathrm{Hz}^{1 / 2}$ at $3 \mathrm{kHz}$ \\
\hline MMS (Le Contel et al. 2016) & 2015 & 0.1 & $1 \mathrm{~Hz}$ to $6 \mathrm{kHz}$ & $20 \mathrm{fT} / \mathrm{Hz}^{1 / 2}$ at $1 \mathrm{kHz}$ \\
\hline MMO (Kasaba et al. 2010) & Future & 0.1 & $0.1 \mathrm{~Hz}$ to $20 \mathrm{kHz}$ & $50 \mathrm{fT} / \mathrm{Hz}^{1 / 2}$ at $1 \mathrm{kHz}$ \\
\hline MMO (Coillot et al. 2010) & Future & 0.1 & 10 to $640 \mathrm{kHz}$ & $8 \mathrm{fT} / \mathrm{Hz}^{1 / 2}$ at $100 \mathrm{kHz}$ \\
\hline Arase (ERG) & 2016 & 0.2 & $1 \mathrm{~Hz}$ to $100 \mathrm{kHz}$ & $20 \mathrm{fT} / \mathrm{Hz}^{1 / 2}$ at $2 \mathrm{kHz}$ \\
\hline
\end{tabular}

is mounted on the top of the MAST along the $+Y$ axis in the SGA coordinates, while the MGF is mounted on a separate mast that extends from the other side. The $\alpha$ and $\beta$ axes are tilted by $45^{\circ}$ from the $X$ and $Y$ axes. The $\gamma$ axis is parallel to the $Z$ (spin) axis. Because of the highradiation environment (over $100 \mathrm{krad}$ ), the MSC-PA is mounted on the $+Y$ panel inside the satellite body.

A block diagram of the MSC is shown in Fig. 3. The AC magnetic field vectors below $20 \mathrm{kHz}$ are digitally processed by the WaveForm Capture (WFC) for the waveform observations and the Onboard Frequency Analyzer (OFA) for the spectrum observations (Kasahara et al. 2018). Additionally, the $B_{\gamma}$ component along the spin axis is measured by the High Frequency Analyzer (HFA) for the spectrum measurements from 10 to $100 \mathrm{kHz}$
(Kumamoto et al. 2018). The NEMI requirements for the plasma wave observations by the Arase satellite are listed in Table 2. The sensor and low-noise preamplifiers were carefully designed to satisfy those requirements.

\section{Sensor}

The one-axis sensor for the MSC-S consists of a magnetic core wound with a solenoid coil of copper wire and is equipped with an electrostatic shield to avoid electric field pickup (Ozaki et al. 2015). The insulator coating on the copper wire and coil bobbin is fabricated from radiation-hardened polyimide plastic designed for use in highradiation environments. An $R L C$ resonant circuit with a resistive component for causing magnetic loss is provided as an equivalent circuit of the one-axis sensor for 


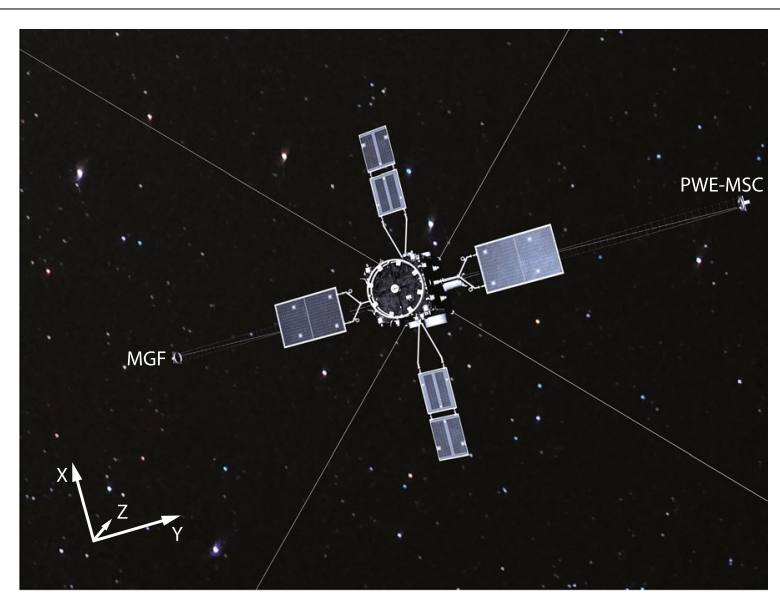

Fig. 1 Arase satellite in the SGA coordinates. The $Z$ axis is located along the satellite spin axis. This figure is a modification of an original version produced by the ERG project

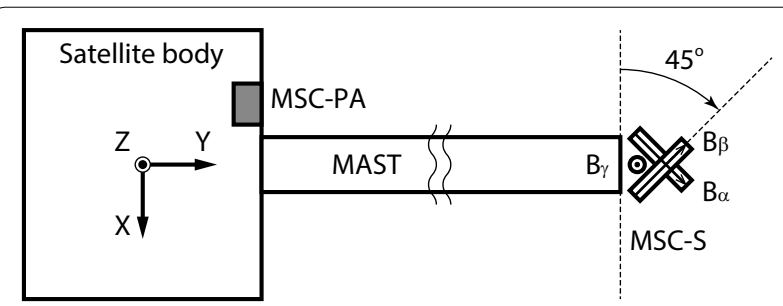

Fig. 2 The $\alpha \beta \gamma$ coordinates for the MSC in the SGA coordinates. The $\gamma$ axis is parallel to the satellite spin axis, and the $\alpha-\beta$ plane is in the satellite spin plane

the MSC-S, as shown in Fig. 4. The sensor impedance $Z_{\mathrm{s}}$ at the coil terminals is expressed as

$$
Z_{\mathrm{s}}=\frac{R+j \omega L}{\left(1-\omega^{2} C L+\frac{R}{R_{\text {loss }}}\right)+j \omega\left(C R+\frac{L}{R_{\text {loss }}}\right)},
$$

where $R, L, C, R_{\text {loss }}$, and $\omega$ are the resistance, inductance, parasitic capacitance of the coil, resistive component for the magnetic losses, and the angular frequency, respectively. The magnitude of the sensor impedance is approximately

$$
\left|Z_{\mathrm{s}}\right| \approx \begin{cases}R & \left(0<f<\frac{R}{2 \pi L}\right) \\ |j \omega L| & \left(\frac{R}{2 \pi L}<f<f_{r}\right) \\ R_{\operatorname{loss}} & \left(f=f_{r}\right) \\ \left|\frac{1}{j \omega C}\right| & \left(f>f_{r}\right)\end{cases}
$$

where

$$
f_{\mathrm{r}}=\frac{1}{2 \pi \sqrt{L C}}
$$

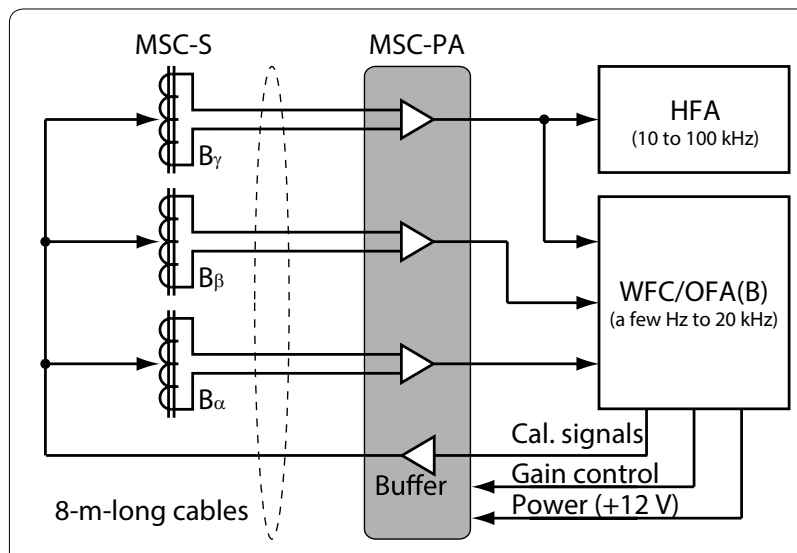

Fig. 3 Block diagram of the MSC on board the Arase satellite

Table 2 NEMI requirements for the MSC

\begin{tabular}{lll}
\hline Frequency $\mathbf{( H z})$ & $\mathbf{N E M I}\left(\mathbf{p T} / \mathbf{H z}^{\mathbf{1 / 2}}\right)$ & Measurement target \\
\hline $1-10$ & $30-3$ & EMIC waves \\
30 & 1 & Magnetosonic waves \\
$2 \mathrm{k}$ & 0.2 & Chorus and hiss waves \\
\hline
\end{tabular}

is the resonant frequency of the coil. To reduce the parasitic capacitance, the coil consists of layers wound in the same direction (Dalessandro et al. 2007). An induced voltage $e$ is given directly from Faraday's law as

$$
\begin{aligned}
& e=-\frac{\mathrm{d} \Phi}{\mathrm{d} t} \\
& =-j \omega \mu_{\mathrm{app}} N S B,
\end{aligned}
$$

where $\Phi$ is the magnetic flux, $\mu_{\text {app }}$ is the apparent permeability of the magnetic core, $N$ is the number of solenoid coil turns, $S$ is the cross-sectional area of the magnetic core, and $B$ is the ambient external magnetic field. Since a conventional magnetic core formed in a square column shape was used on the MSC on board the Arase satellite, the apparent permeability is

$$
\frac{1}{\mu_{\mathrm{app}}}=\frac{1}{\mu_{\mathrm{i}}}+\left(\frac{d}{l}\right)^{2}\left(\ln \left(\frac{2 l}{d}\right)-1\right)\left(1-\frac{1}{\mu_{\mathrm{i}}}\right),
$$

where $\mu_{\mathrm{i}}, l$, and $d$ are the initial permeability, the length, and the side length of the core, respectively (Séran and Fergeau 2005). Basic parameters of the MSC-S are listed in Table 3. The mass of the one-axis sensor for the MSC-S with a 200-mm-long core was $91 \mathrm{~g}$, which is almost the same as the 100-mm-long sensor on board the MMO satellite. The mass saving for the MSC-S was realized by an optimization of magnetic wire (the number of turns and 


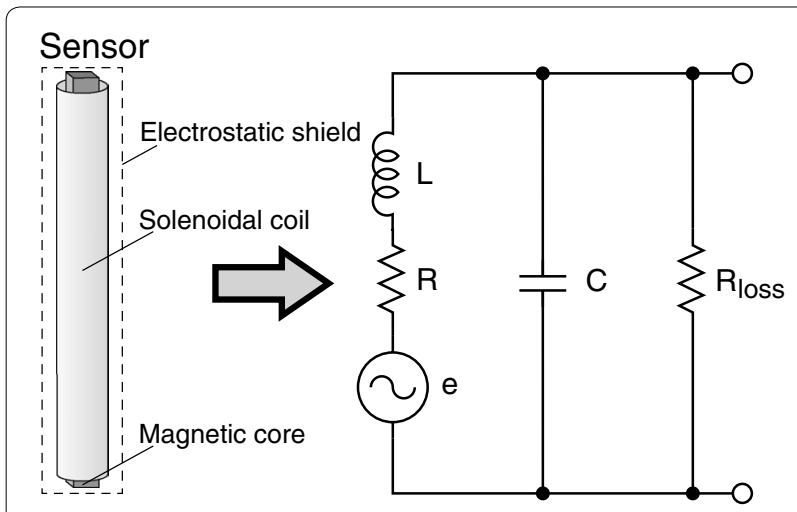

Fig. 4 Equivalent circuit of the one-axis sensor for the MSC-S

Table 3 Parameters for the MSC-S

\begin{tabular}{lll}
\hline Item & Value & Unit \\
\hline Mass of the one-axis sensor & 91 & $\mathrm{~g}$ \\
$\begin{array}{l}\text { Magnetic core (permalloy) } \\
\text { Apparent permeability of the }\end{array}$ & $5 \times 5 \times 200$ & $\mathrm{~mm}$ \\
$\quad$ magnetic core & 452 & \\
$\begin{array}{l}\text { Magnetic wire diameter } \\
\begin{array}{l}\text { Number of turns for the sole- } \\
\text { noid coil }\end{array}\end{array}$ & $\begin{array}{l}14,000 \\
\text { Electrostatic shield }\end{array}$ & $\mathrm{mm}$ \\
& Al plate (thickness 0.2 mm) with & turns \\
& two slits & \\
\hline
\end{tabular}

the diameter), which was designed such that the thermal noise levels of resistive component should be less than the noise property of preamplifier.

\section{MAST}

The three sensors of the MSC-S are orthogonally assembled on a top plate to detect magnetic field vectors. The top plate is made of carbon fiber-reinforced plastic (CFRP)/aluminum honeycomb sandwich panel (CFRP surface thickness $1.1 \mathrm{~mm}$ and honeycomb thickness $10 \mathrm{~mm}$ ) to reduce the eddy current losses on the plate. A thermistor is attached on the top plate to provide the temperature of the MSC-S as housekeeping data. The MSC-S is mounted on the top of the MAST to mitigate electromagnetic noises from the satellite body. Finally, the MSC-S is covered by a multilayered insulator (MLI) to isolate it thermally from the space environment. The total mass of the MAST equipped with the MSC-S is $3.8 \mathrm{~kg}$.

Figure 5a, b shows photographs of the MSC-S installed on the top of the MAST in both stowed and extended positions. In a ground test for full extension, the
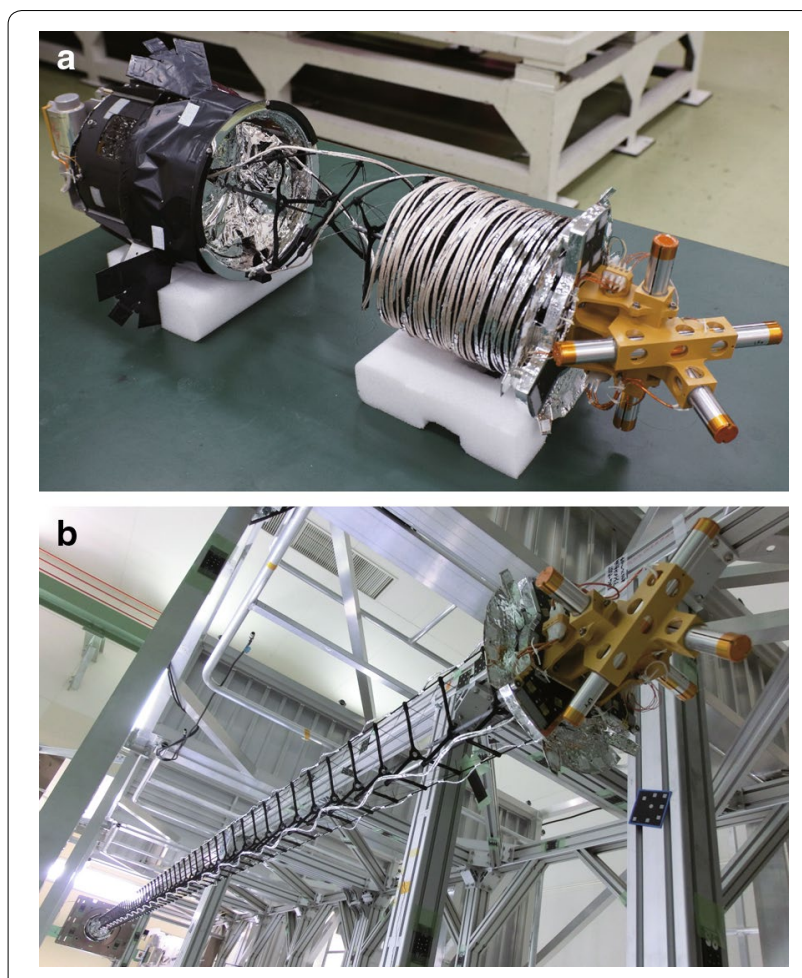

Fig. 5 Photographs of the MSC-S mounted on the top of the MAST in both $\mathbf{a}$ stowed and $\mathbf{b}$ extended positions. The length of the MAST in full extension is $5.2 \mathrm{~m}$ from the side panel of the satellite body

mechanical alignment accuracy of the MAST was found to be within $2^{\circ}$ in the $\alpha \beta \gamma$ coordinates. Wave-normal and Poynting vectors can be measured with accuracy levels within a few degrees. Wave-normal and Poynting vectors, along with polarizations, are useful for determining the generation regions of plasma waves (e.g., Nagano et al. 1996; Santolík et al. 2003; Horne et al. 2007).

\section{Preamplifier}

Preamplifiers for search coil magnetometers can be classified into two types: one uses a voltage amplifier with flux feedback (e.g., Matsumoto et al. 1994), and the other uses a current amplifier with an equalizer (e.g., Ozaki et al. 2014). While most preamplifiers used in previous missions were the voltage-sensing type, the currentsensing type was adopted for the MSC-PA to reduce the wire harness between the MSC-PA installed in the satellite body and the MSC-S at the top of the MAST. When an induction coil sensor is connected to an ideal current amplifier, the parasitic capacitance between the coil terminals is virtually shorted. This allows resonance to be effectively eliminated without the flux feedback coil that is used for damping in voltage-sensing type preamplifiers. 


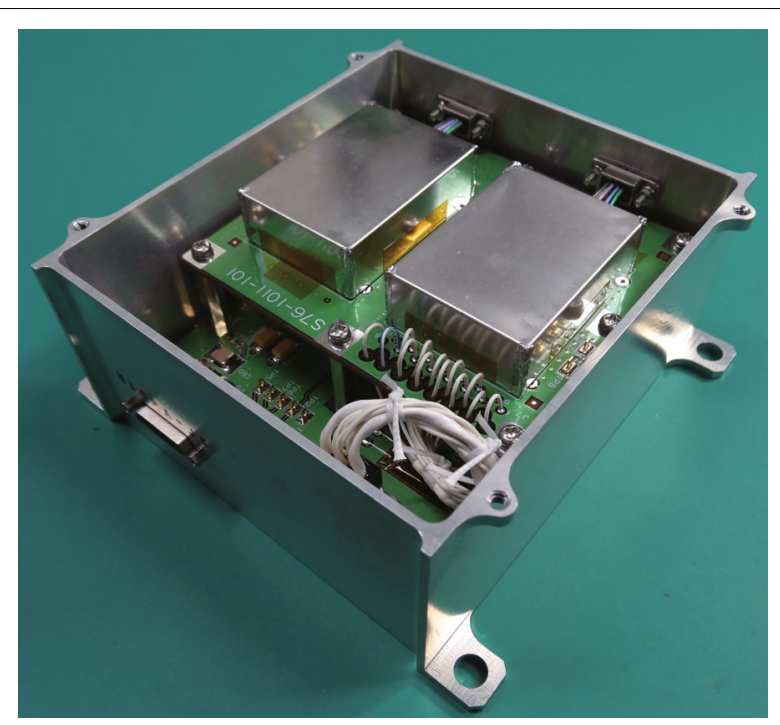

Fig. 6 Photograph of the MSC-PA. The size of chassis is $110 \times 125 \times 60 \mathrm{~mm}$ (protruding parts not included)

As a result, the harness for the flux feedback coils can be eliminated in the current-sensing type.

The MSC-PA consists of three sets of low-noise current amplifiers, equalizers, and gain adjustment amplifiers. The MSC-PA has a buffer amplifier to apply calibration signals to the sensors from the main electronics box of the PWE. The design concept behind the low-noise current amplifier and equalizer is based on the preamplifier on board the MMO satellite (Kasaba et al. 2010). The gain adjustment amplifier can select $0-$ or $20-\mathrm{dB}(\times 1$ or $\times 10)$ voltage gains to prevent saturation by large-amplitude chorus waves (Cattell et al. 2008), which can reach amplitudes up to several nT. The saturation levels of low $(0 \mathrm{~dB})$ and high $(20 \mathrm{~dB})$ gain cases are 10 and $1 \mathrm{nT}$ at a frequency of $1 \mathrm{kHz}$, respectively.

Figure 6 shows a photograph of the MSC-PA housed in aluminum chassis (side and top thickness $2 \mathrm{~mm}$; bottom thickness $3 \mathrm{~mm}$ ). The thickness was calculated to satisfy the total ionizing dose limit of $100 \mathrm{krad}$ during the nominal mission life (1 year). The electrical circuits for $B_{\alpha}$ and the buffer amplifier are installed on the bottom printed circuit board (PCB) and the circuits for $B_{\beta}$ and $B_{\gamma}$ are installed on the top PCB. The electrical circuits for each magnetic field component are electrically protected by internal shield boxes to reduce internal crosstalk and improve radiation tolerance. The mass of the MSC-PA, including the chassis, is $0.6 \mathrm{~kg}$. The nominal power consumption is $0.43 \mathrm{~W}$. A heater and a thermometer for house keeping are attached to the top of the chassis.

\section{Results and discussion}

\section{Transfer function and NEMI}

The transfer function measurements of $B_{\alpha}, B_{\beta}$, and $B_{\gamma}$ for the low- and high-gain cases are plotted in Fig. 7. These measurements were performed using a 1-m-diameter Helmholtz coil in a magnetically shielded room at Kanazawa University. The results show a good agreement among three axes. More specifically, the difference is less than $1 \mathrm{~dB}$ except the lowest frequency end. The shape of the transfer function is similar to that for a search coil magnetometer using a typical voltage amplifier in the frequency domain. Because it focuses fundamentally on the measurements of chorus and hiss waves below the equatorial gyrofrequency (typically several $\mathrm{kHz}$ ), the MSC was designed to have the resonant frequency of $2 \mathrm{kHz}$. The resonance is effectively damped by the current amplifier, and the transfer function is adjusted by the equalizer. The gain less than $1 \mathrm{~Hz}$ is proportional to $\omega^{2}$ to avoid signal saturation caused by the background geomagnetic field at the satellite spin rate (approximately $1 / 8 \mathrm{~Hz}$ ). The gain between 1 and $500 \mathrm{~Hz}$ is proportional to $\omega$ based on Faraday's law. The use of the current amplifier on board the Arase satellite is the first in the satellite experiments for the radiation belts.

Figure 8 shows the NEMI of the MSC for the $\gamma$ component, which is least influenced by the satellite spin modulation. Here, it can be seen that the NEMI sufficiently satisfies the requirements of the Arase satellite listed in Table 2. The best NEMI is $20 \mathrm{fT} / \mathrm{Hz}^{1 / 2}$ at $2 \mathrm{kHz}$, which is sufficient for the observations of chorus and hiss waves. The onboard NEMI (light blue) curve was calculated as an average of 29 sets of 16-s waveform data observed on March 19, 2017, from 01:01 to 01:37 UT, during which magnetic activity was very low. The onboard NEMI (red) curve was also calculated as an average of 30 sets of 2-s waveform data during 02:19 to 02:34 UT. The NEMI can be shown up to a frequency of $20 \mathrm{kHz}$ due to the antialiasing filter of the WFC receiver. The green and blue curves were obtained from the averaged spectra by the OFA and HFA observed during 02:25 and 02:30 UT. These NEMI curves showed quite similar levels to the ground data (black). For reference purposes, the NEMI for the Van Allen Probes (Kletzing et al. 2013) and the typical ranges of intensity and frequency of the plasma waves are also shown in Fig. 8. The difference in NEMI between the Arase satellite and the Van Allen Probes is caused by the difference in sensor length. As listed in Table 1, the core length for the Van Allen Probes is twice as long as that for the Arase satellite. A longer core yields a higher value of the apparent permeability as expected from Eq. (6). However, the NEMI differences between the Arase satellite and the Van Allen Probes have no practical impact on the observations of chorus and hiss waves. 


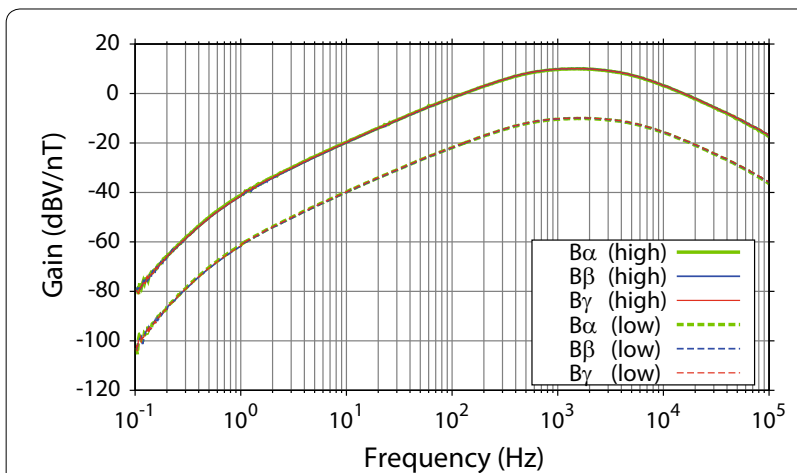

Fig. 7 Gain measurement results for the outputs of the MSC-PA in $\mathrm{dBV} / \mathrm{nT}(0 \mathrm{dBV} / \mathrm{nT}=1 \mathrm{~V} / \mathrm{nT})$

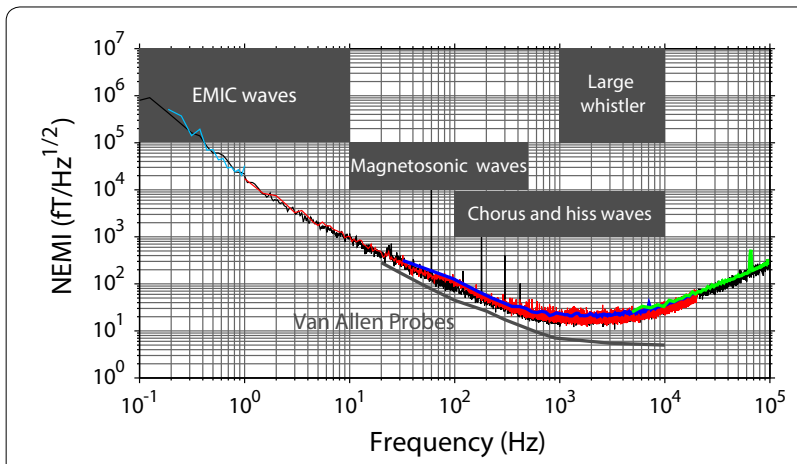

Fig. 8 Measured NEMI curves for the $B_{\gamma}$ component. The black curve is the laboratory experiment result on the ground. The light blue and red curves were obtained from the WFC observed on March 19, 2017, from 01:01 to 01:37 and 02:19 to 02:34 UT, during which plasma wave activity was very low. The blue and green curves were obtained from the OFA and HFA observed during 02:25 to 02:30 UT. The gray curve indicates the NEMI for the Van Allen Probes (Kletzing et al. 2013). Gray boxes are typical plasma wave spectra provided for reference. NEMI curves for the other axes showed almost the same levels

\section{Crosstalk and directionality}

A three-dimensional simulation was performed using an electromagnetic solver (PHOTO-EDDYj $\omega$ ) based on the finite element method to determine an acceptable gap between each sensor. Figure 9 shows the simulation model used for the crosstalk. Note that only three magnetic cores orthogonally crossed each one-axis core with a same gap length are modeled in the simulation box, and the effects of the eddy current on conductive materials were neglected to conserve computer memory in the simulation. Nevertheless, this model is considered adequate for evaluating crosstalk because magnetic flux behavior is predominantly affected by the magnetic core. The magnetic flux for each core is computed by applying uniform magnetic field vectors along the $\alpha$ axis. The crosstalk value is calculated as

$$
\begin{aligned}
C T & =20 \log _{10}\left(\frac{\int_{\text {core }} \boldsymbol{B} \cdot \mathrm{d} \boldsymbol{S}_{\boldsymbol{\beta}}}{\int_{\text {core }} \boldsymbol{B} \cdot \mathrm{d} \boldsymbol{S}_{\boldsymbol{\alpha}}}\right) \\
& =20 \log _{10}\left(\frac{\int_{\text {core }} \boldsymbol{B} \cdot \mathrm{d} \boldsymbol{S}_{\boldsymbol{\gamma}}}{\int_{\text {core }} \boldsymbol{B} \cdot \mathrm{d} \boldsymbol{S}_{\boldsymbol{\alpha}}}\right),
\end{aligned}
$$

where the boldface type indicates a vector and $\mathrm{d} S$ is an area element for each core. To obtain accurate magnetic field vectors with a direction error less than a few degrees, the crosstalk between each component should be less than $-40 \mathrm{~dB}$.

Figure 10 shows the results of simulated crosstalk between the magnetic cores as a function of the gap length. The size of each one-axis core is $5 \times 5 \times 200 \mathrm{~mm}$, which is the same as that of the magnetic core for the MSC-S. The simulations were performed for three cases of magnetic permeability $\left(\mu_{\mathrm{i}}=1000,2000\right.$, and 10,000). The crosstalk values for $\mu_{\mathrm{i}}=1000,2000$, and 10,000 are $-47.2,-45.7$, and $-44.4 \mathrm{~dB}$ for the gap of $20 \mathrm{~mm}$, respectively.

The measurement results obtained using the engineering model for the MSC-S $\left(\mu_{\mathrm{i}}=10,000\right)$ are added to Fig. 10 for reference to the simulation case of $\mu_{\mathrm{i}}=10,000$. The measurements were evaluated by comparing the output voltages between parallel and perpendicular arrangements for the standard magnetic field vector generated by a Helmholtz coil. Differences between the simulation and measurement results were due to inaccuracy of sensor alignment because crosstalk is sensitive to the sensor geometry. Here, the apparent permeability coefficients of the one-axis magnetic core $(5 \times 5 \times 200 \mathrm{~mm})$ for $\mu_{\mathrm{i}}=1000,2000$, and 10,000 are calculated as 321, 383, and 452, respectively, from Eq. (6). One interesting point is that the crosstalk ratio for the three magnetic permeability cases in the simulation is almost constant when the gap is over $15 \mathrm{~mm}$. This implies that crosstalk differences for each gap are indirectly related to apparent permeability.

To confirm the relationship between the crosstalk and apparent permeability, we calculated the ratio of the crosstalk for each initial permeability and that of the apparent permeability. These ratios as a function of the gap are shown in Fig. 11. From the comparison results, we found that when the gap is over $15 \mathrm{~mm}$, the crosstalk ratios between $\mu_{\mathrm{i}}=2000$ and $\mu_{\mathrm{i}}=1000$, and those between $\mu_{\mathrm{i}}=10,000$ and $\mu_{\mathrm{i}}=1000$ showed a good similarity with the ratios of the apparent permeability because the magnetic coupling between the cores decreases with the increasing gap. The crosstalk depends strongly on the apparent permeability. Finally, the MSC-S was designed with a gap length of $18 \mathrm{~mm}$. Although sensor geometry is usually determined by trial and error, our understanding of this crosstalk dependence on apparent permeability 

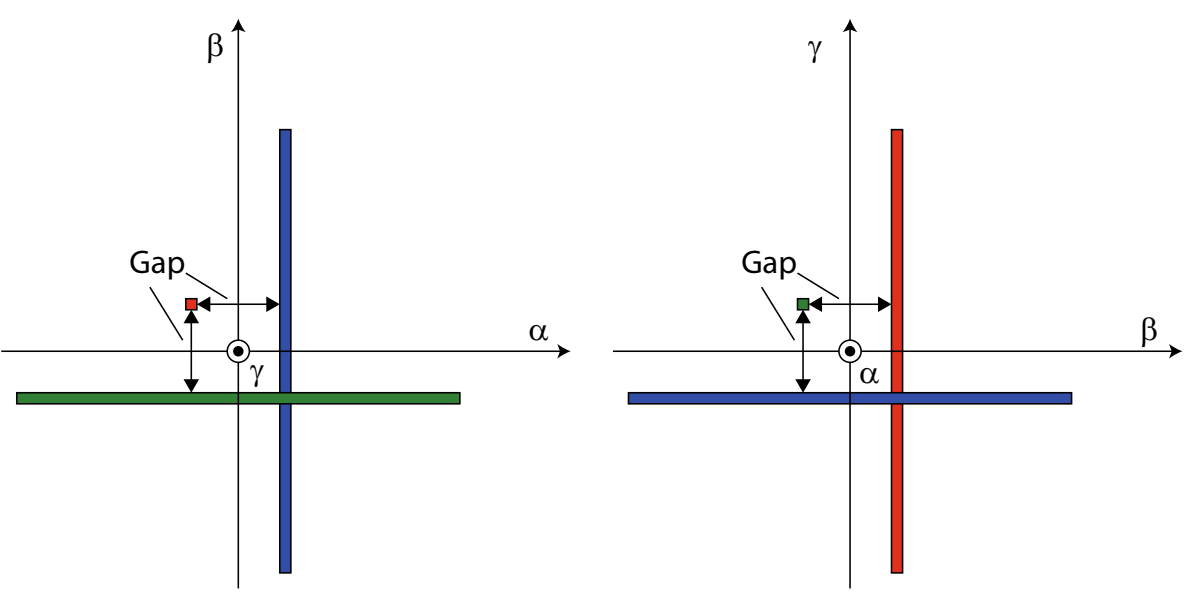

Fig. 9 Sensor geometry for crosstalk simulations

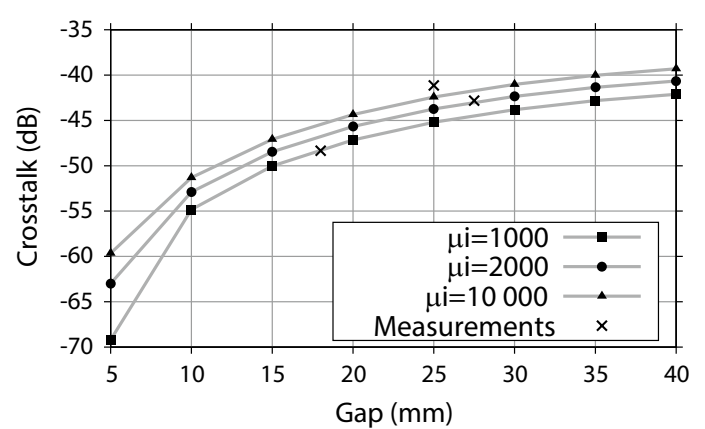

Fig. 10 Simulation results of crosstalk for the three-axis magnetic cores. The laboratory measurements ( $\mu_{\mathrm{i}}=10,000$, length $=200 \mathrm{~mm}$, cross-sectional area $=5 \times 5 \mathrm{~mm}$, and gap $=18,25$, and $28 \mathrm{~mm}$ ) are added for reference

allows us to design a triaxial sensor geometry with an acceptable level of crosstalk.

Next, the measurement results of the directionality of the MSC for each gain mode are plotted in Fig. 12. These measurements are normalized by the maximum value to clearly show the null depth in unit of $\mathrm{dB}$. Although directionality is usually measured by rotating a sensor emplaced on a turntable, these measurements were performed by rotating the input magnetic field vector for the MSC-S with an angular resolution of $0.5^{\circ}$. An arbitrary direction of a magnetic field vector was generated by using a three-axis Helmholtz coil. This had the advantage for reducing the alignment errors of the MSC-S on the turntable and achieving a higher angular resolution. All measurements show a clear null depth less than $-40 \mathrm{~dB}$, which is consistent with the crosstalk simulation results.

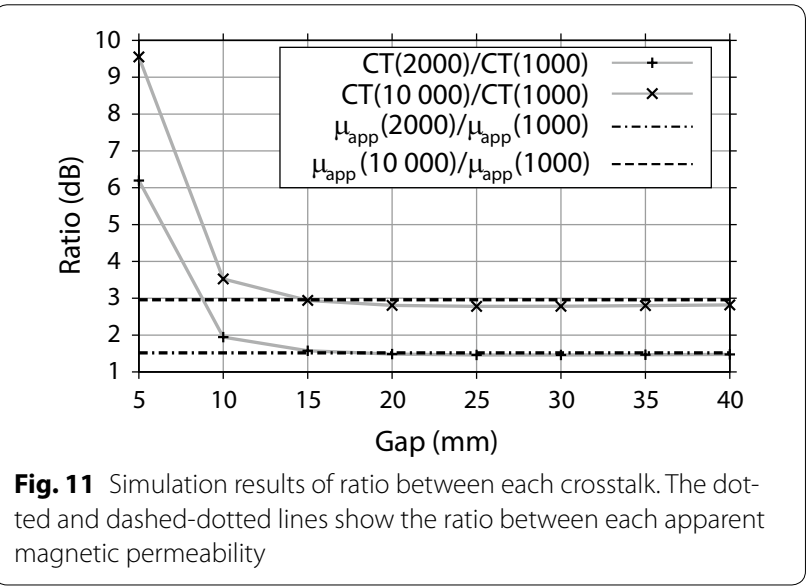

\section{Calibration}

Onboard calibration is performed to identify the validity of the transfer function of the MSC in the radiation belts. Continuous square waves, which are used as calibration signals, are supplied to the calibration coils at an arbitrary frequency through the buffer amplifier of the MSC-PA as shown in Fig. 3. The transfer function is obtained at the fundamental frequency and its harmonics. An example of an onboard calibration conducted on March 10, 2017, at 23:39 UT with 512-Hz square waves is shown in Fig. 13. The top panel shows the output waveform for the onboard calibration. The buffer amplifier consists of a low-pass filter for mitigating the effect of induction voltage (time derivative of the applied magnetic field for calibration) appearing as the discontinuity in the square pulses. When applying square pulses, the output waveform looks like a row of shark teeth. In the bottom panel, the black line indicates the laboratory experiment result and the dots denote the onboard calibration results at $512 \mathrm{~Hz}$ and its harmonics. The onboard 
calibration output shows a good agreement with the laboratory experiment data. The use of harmonics is effective for obtaining not only the signal power, but also the phase information in a wide frequency band (Matsuda et al. 2018). Such a use of harmonics was adopted in the calibration of the search coil magnetometers on board the Time History of Events and Macroscale Interactions during Substorms (THEMIS) satellites (Roux et al. 2008).

Additionally, cross-calibration between the MSC and MGF is important for verifying the health of both instruments at frequencies less than $10 \mathrm{~Hz}$. Figure 14 shows the intensity variations of geomagnetic field in the $X-Y$ (spin) plane observed by the MSC and the MGF during 01:00 to 01:40 UT, March 19, 2017. The intensity of background geomagnetic field measured by the MSC is obtained from the satellite spin modulation component in the waveform data. Since the alignment error offsets between the MSC and the MGF were not corrected, the intensity difference between them was a few $\%$ in the spin plane. The difference is comparable to the cross-calibration results of the other missions (Robert et al. 2014). These differences can be improved by correcting the alignment errors of the MAST. Furthermore, this good agreement indicates that the MSC was not affected by Barkhausen noise, in which noise signals are generated when a suddenly changing magnetic field is applied to a magnetic core. These results indicate that the MSC can cooperate with the MGF in the background geomagnetic field observations.

\section{Extension operation for the MAST}

Figure 15 shows the magnetic field spectrum measured during the extension operation for the MAST conducted on January 17, 2017. To prevent disturbances to the
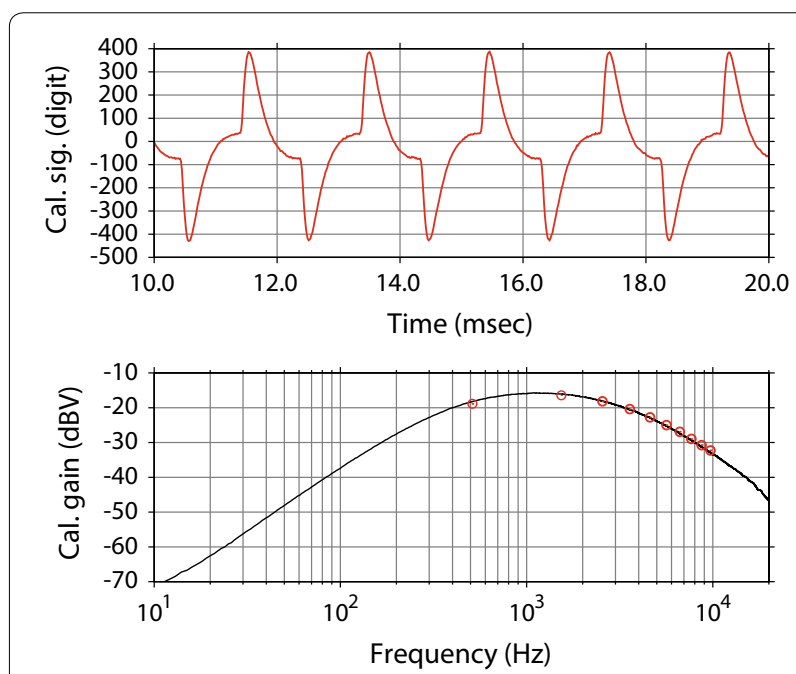

Fig. 13 Example of the onboard calibration result of the $B_{\gamma}$ component. The upper panel is the waveform obtained at 23:39 UT, March 10, 2017, by the WFC for applied square pulses having a fundamental frequency of $512 \mathrm{~Hz}$. The bottom panel shows the gain of the onboard calibration (dots) at the fundamental frequency and its harmonics. The black line indicates the gain measured by a laboratory experiment for reference

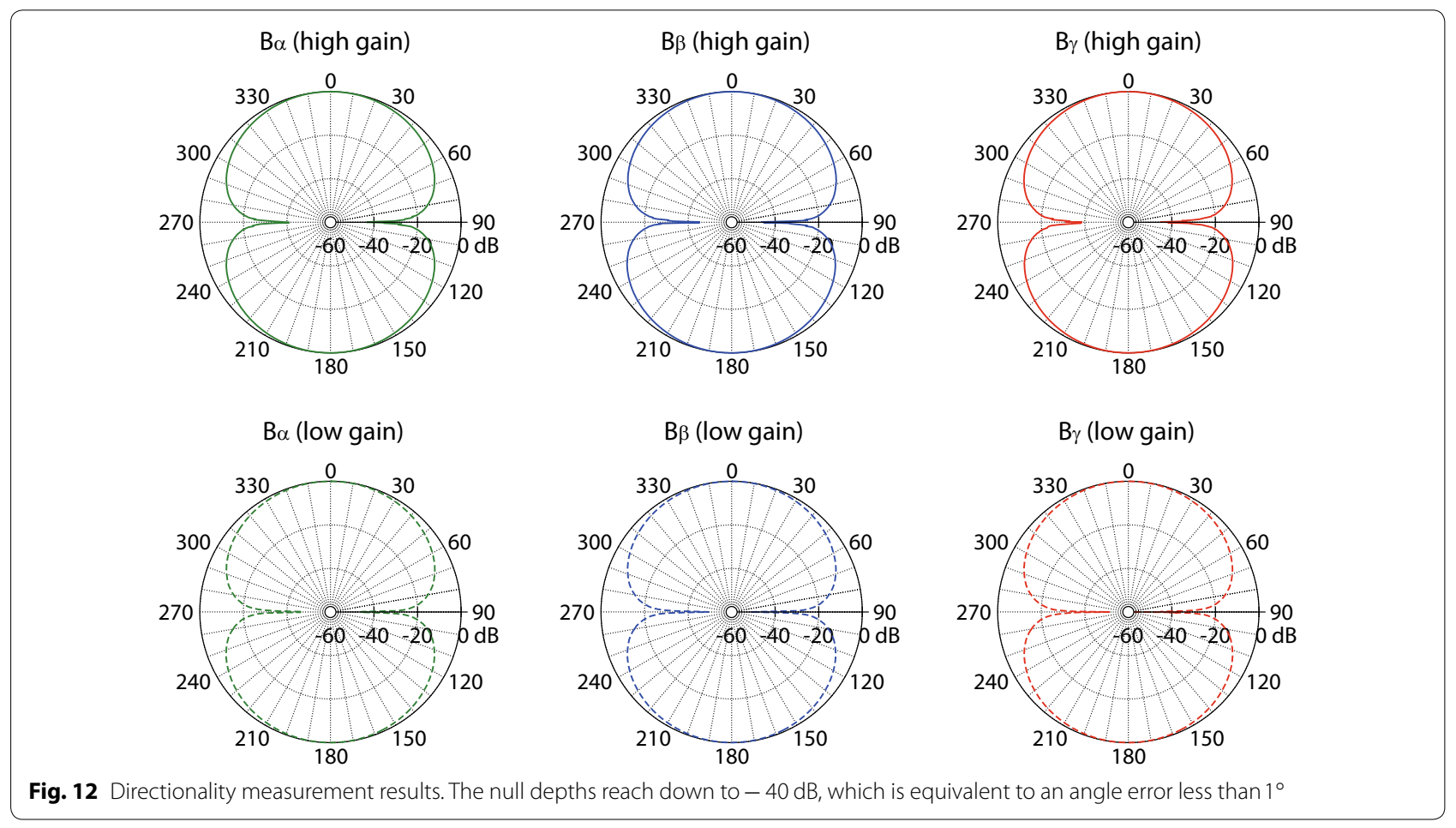




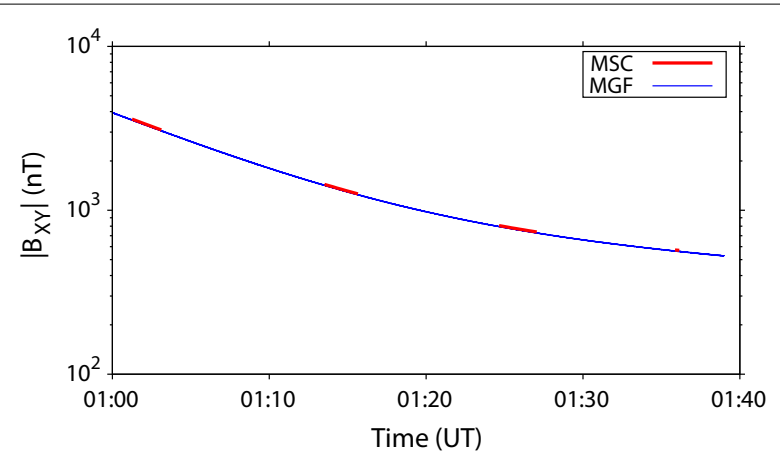

Fig. 14 Comparison of geomagnetic field values in the $X-Y$ plane observed by the MSC and MGF for the period of 01:00-01:40 UT on March 19, 2017

satellite's attitude, the MAST was partially extended to $0.3 \mathrm{~m}$ at 21:15 UT and then fully extended up to $5 \mathrm{~m}$ during the period from 21:37 to $21: 45$ UT. Noise enhancements detected at 21:15 UT and from 21:37 to 21:45 UT were caused by motor current during the extension process. Figure 16 shows the 1 -min averaged intensities $\left(|B|=\sqrt{\left.\left|B_{\alpha}\right|^{2}+\left|B_{\beta}\right|^{2}+\left|B_{\gamma}\right|^{2}\right)}\right.$ at 21:00 UT as a typical pre-extension intensity, at 21:30 UT for the partial extension $(0.3 \mathrm{~m})$, and at 21:55 UT after full extension $(5 \mathrm{~m})$. The averaged noise attenuation ratio below $300 \mathrm{~Hz}$ was $7 \mathrm{~dB}$ for the partial extension $(0.3 \mathrm{~m})$, and the magnetic field intensity was found to have decreased to the NEMI level as a result of attenuation over $25 \mathrm{~dB}$ after full extension $(5 \mathrm{~m})$. The attenuation ratios for a line current source and a small magnetic dipole are proportional to $1 / r^{2}$ and $1 / r^{3}$, respectively, where $r$ is the distance between the MSC-S and a noise source. Therefore, a noise less than a few hundred $\mathrm{Hz}$ may be caused by a small magnetic dipole inside the satellite body. On the other hand, the averaged noise attenuation ratios around $1 \mathrm{kHz}(800-$ $1200 \mathrm{~Hz}$ ) were approximately $4 \mathrm{~dB}$ for partial extension

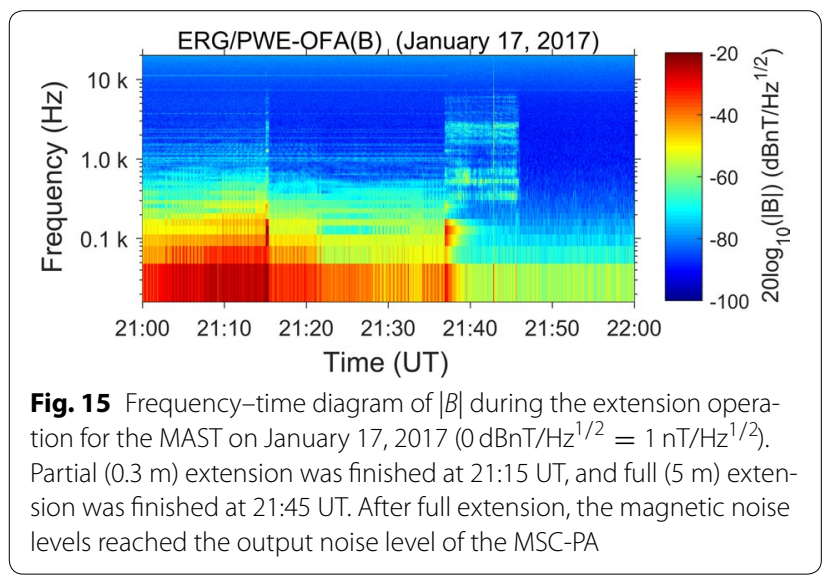

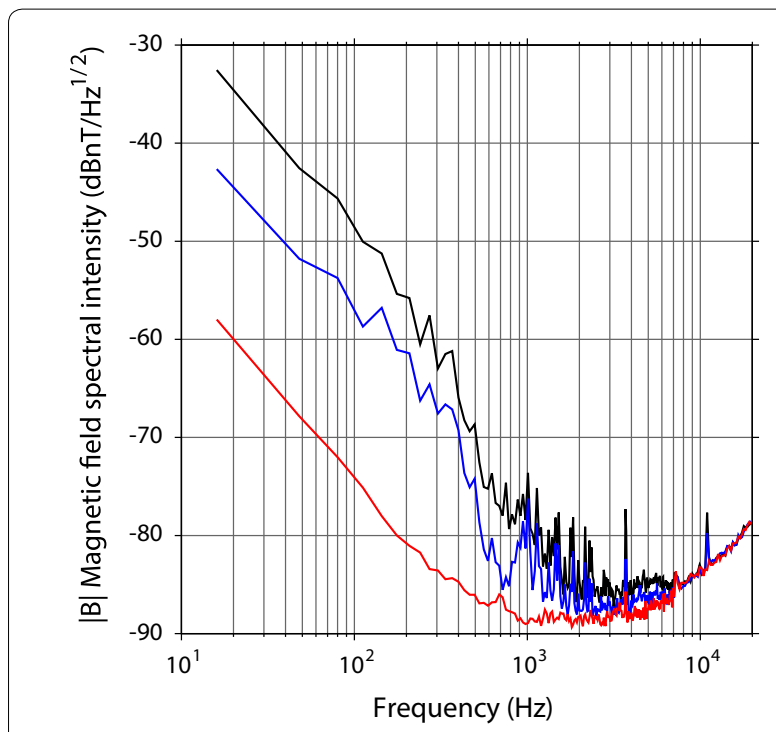

Fig. 16 Magnetic field spectral intensity during the extension operation for the MAST. The black, blue, and red lines are the typical intensities before extension, during partial extension, and after full extension

and $10 \mathrm{~dB}$ after full extension. The noise around $1 \mathrm{kHz}$ $(800-1200 \mathrm{~Hz})$ would be radiated from a line source (e.g., current lines from solar paddles). Ultimately, as a result of the successful extension operation for the MAST, we are able to conduct magnetic field observations with good low-noise properties.

\section{Initial observation result}

Figure 17 shows an example of dynamic spectrum of magnetic field observed at 04:36 UT, March 21, 2017. As can be seen in the figure, clear fine structures of successive rising tone elements of chorus waves with a high signal-to-noise ratio were observed near the plasmapause. Simultaneously, pulsating aurora was observed near the magnetic conjugate point (the Arase location was $L \approx 6.2$ ), Husafell, Iceland (not shown in this paper). The behavior of chorus waves is not only important for understanding radiation belt dynamics, but also for understanding the generation mechanism of pulsating aurora (Nishimura et al. 2010).

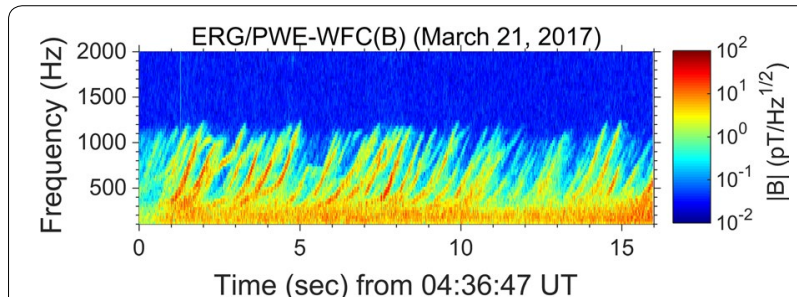

Fig. 17 Example of initial observations of chorus waves conducted at 04:36 UT, March 21, 2017 


\section{Conclusions}

In this paper, the detailed performance characteristics of the MSC on board the Arase satellite were presented. The MSC was designed and developed to provide accurate magnetic field vectors when used in a high-radiation environment. The NEMI is $1 \mathrm{pT} / \mathrm{Hz}^{1 / 2}$ at $10 \mathrm{~Hz}$ and $20 \mathrm{fT} / \mathrm{Hz}^{1 / 2}$ at $2 \mathrm{kHz}$, which satisfy the scientific requirement levels of the mission. The gain has two modes to prevent saturation (10 $\mathrm{nT}$ for $0 \mathrm{~dB}$ and $1 \mathrm{nT}$ for $20 \mathrm{~dB}$ at $1 \mathrm{kHz}$ ) when encountering plasma waves with an unusually large amplitude in the radiation belts. The MSC will help further understanding of the characteristics and activities of plasma waves in radiation belt dynamics.

\section{Authors' contributions}

MO developed the MSC and wrote the whole of this paper. YS designed the concept of current-sensitive preamplifier of the MSC. YK was a principal investigator of the PWE. HK and YK were co-principal investigators of the PWE. AK and FT developed the HFA receiver. SM managed the PWE data. AM was a principal investigator of the MGF and conducted the MAST extension. TS and TY manufactured the flight models of the MSC and MAST. All authors read and approved the final manuscript.

\section{Author details}

${ }^{1}$ Graduate School of Natural Science and Technology, Kanazawa University, Kakuma-machi, Kanazawa 920-1 192, Japan. ${ }^{2}$ Research Institute for Sustainable Humanosphere, Kyoto University, Gokasho, Uji 611-0011, Japan. ${ }^{3}$ Graduate School of Science, Tohoku University, Aoba, Sendai 980-8578, Japan. ${ }^{4}$ Institute for Space-Earth Environmental Research, Nagoya University, Chikusa-ku, Nagoya 464-8601, Japan. ${ }^{5}$ Institute of Space and Astronautical Science, Yoshinodai, Sagamihara 252-5210, Japan. ${ }^{6}$ Aerospace Division, NIPPI Corporation, 3175 Showa-machi, Kanazawa-ku, Yokohama 236-8540, Japan.

\section{Acknowledgements}

This study was supported by a Grant-in-Aid for Young researchers from the Hokuriku Bank, Ltd. A part of this study was carried out under the joint research program of the Solar-Terrestrial Environment Laboratory, Nagoya University, and by the Japan Society for the Promotion of Science (JSPS) KAKENHI Grant Number 16H04056. The authors would like to extend sincere thanks to Mr. T. Kitase, Mr. A. Asano, and Mr. Y. Tokunaga for their efforts in the laboratory experiments and magnetic field simulations. Gratitude is also extended to Mr. H. Tanakano of the Meiwa System and Mr. Y. Sato for developing the breadboard model of the MSC, and to Dr. S. Nakazawa and Dr. M. Mita of the ISAS/JAXA for their support during the electromagnetic compatibility tests. The authors would also like to thank Dr. I. Nagano, Dr. G. Chanteur, and Dr. C. Coillot for their valuable discussions on the MSC, the NIPPI corp. members involved in the MSC, and the Mitsubishi Heavy Industries, Ltd. and Meisei Electric Co., Ltd. engineers that participated in developing the PWE. Finally, the authors would like to thank all members of the ERG project and the ERG Science Center.

\section{Competing interests}

The authors declare that they have no competing interests.

\section{Availability of data and materials}

The PWE and MGF data will be available through the ERG Science Center operated by ISAS/JAXA and ISEE/Nagoya University.

\section{Ethics approval and consent to participate}

Not applicable.

\section{Publisher's Note}

Springer Nature remains neutral with regard to jurisdictional claims in published maps and institutional affiliations.
Received: 22 August 2017 Accepted: 14 April 2018

Published online: 04 May 2018

\section{References}

Anderson RR, Gurnett DA, Odem DL (1992) CRRES plasma wave experiment. J Spacecr Rockets 29:570-573

Baker DN, Blake JB, Klebesadel RW, Higbie PR (1986) Highly relativistic electrons in the Earth's outer magnetosphere: 1. Lifetimes and temporal history 1979-1984. J Geophys Res 91:4265-4276. https://doi.org/10.1029/ JA091iA04p04265

Baker DN, Kanekal SG, Hoxie VC, Henderson MG, Li X, Spence HE, Elkington SR, Friedel RHW, Goldstein J, Hudson MK, Reeves GD, Thorne RM, Kletzing CA, Claudepierre SG (2013) A long-lived relativistic electron storage ring embedded in Earth's outer Van Allen belt. Science 340:186-190. https:// doi.org/10.1126/science.1233518

Bougeret J-L, Kaiser ML, Kellogg PJ, Manning R, Goetz K, Monson SJ, Monge N, Friel L, Meetre CA, Perche C, Sitruk L, Hoang S (1995) WAVES: the radio and plasma wave investigation on the wind spacecraft. Space Sci Rev 71:231-263

Blęki J, Gadomski S, Juchniewicz J, Korepanov V, Krawczyk Z, Savin S, Słomiński J, Triska P, Vojta J, Wronowski R (1997) SAS wave experiment on board Magion 4. Ann Geophys 15:528-532

Burtis WJ, Helliwell RA (1969) Banded chorus - a new type of VLF radiation observed in the magnetosphere by OGO 1 and OGO 3. J Geophys Res 74:3002-3010. https://doi.org/10.1029/JA074i011p03002

Cattell C, Wygant JR, Goetz K, Kersten K, Kellogg PJ, von Rosenvinge T, Bale SD, Roth I, Temerin M, Hudson MK, Mewaldt RA, Wiedenbeck M, Maksimovic M, Ergun R, Acuna M, Russell CT (2008) Discovery of very large amplitude whistler-mode waves in Earth's radiation belts. Geophys Res Lett 35:L01105. https://doi.org/10.1029/2007GL032009

Coillot C, Moutoussamy J, Lebourgeois R, Ruocco S, Chanteur G (2010) Principle and performance of a dual-band search coil magnetometer: a new instrument to investigate fluctuating magnetic fields in space. IEEE Sens J 10:255-260

Cornilleau-Wehrlin N, Chanteur G, Perraut S, Rezeau L, Robert P, Roux A, De Villedary C, Canu P, Maksimovic M, De Conchy Y, Hubert D, Lacombe C, Lefeuvre F, Parrot M, Pinçon JL, Décréau PME, Harvey CC, Louarn Ph, Santolik O, Alleyne H, St C, Roth M, Chust T, Le Contel O (2003) First results obtained by the Cluster STAFF experiment. Ann Geophys 21:437-456

Dalessandro L, da Silveira Cavalcante F, Kolar JW (2007) Self-capacitance of high-voltage transformers. IEEE Power Electron 22:2081-2092

Elkington SR, Hudson MK, Chan AA (1999) Acceleration of relativistic electrons via drift-resonant interaction with toroidal-mode PC-5 ULF oscillations. Geophys Res Lett 26:3273-3276. https://doi.org/10.1029/1999GL003659

Elphic RC, Means JD, Snare RC, Strangeway RJ, Kepko L, Ergun RE (2001) Magnetic field instruments for the fast auroral snapshot explorer. Space Sci Rev 98:151-168

Frandsen AMA, Holzer RE, Smith EJ (1969) OGO search coil magnetometer experiments. IEEE Trans Geosci Electron 7:61-74

Fukuhara H, Kojima H, Ueda Y, Omura Y, Katoh Y, Yamakawa H (2009) A new instrument for the study of wave-particle interactions in space: one-chip wave-particle interaction analyzer. Earth Planets Space 61:765-778. https://doi.org/10.1186/BF03353183

Fukunishi H, Toya T, Koike K, Kuwashima M, Kawamura M (1981) Classification of hydromagnetic emissions based on frequency-time spectra. J Geophys Res 86:9029-9039. https://doi.org/10.1029/JA086iA11p09029

Fukunishi H, Fujii R, Kokubun S, Hayashi K, Tohyama T, Tonegawa Y, Okano S, Sugiura M, Yumoto K, Aoyama I, Sakurai T, Saito T, lijima T, Nishida A, Natori M (1990) Magnetic field observations on the Akebono (EXOS-D) satellite. J Geomagn Geoelectr 42:385-409

Gurnett DA, Frank LA, Lepping RP (1976) Plasma waves in the distant magnetotail. J Geophys Res 81:6059-6071. https://doi.org/10.1029/ JA081i034p06059

Gurnett DA, Kurth WS, Shaw RR, Roux A, Gendrin R, Kennel CF, Scarf FL, Shawhan SD (1992) The Galileo plasma wave investigation. Space Sci Rev 60:341-355 
Gurnett DA, Persoon AM, Randall RF, Odem DL, Remington SL, Averkamp TF, Debower MM, Hospodarsky GB, Huff RL, Kirchner DL, Mitchell MA, Pham BT, Phillips JR, Schintler WJ, Sheyko P, Tomash DR (1995) The POLAR plasma wave instrument. Space Sci Rev 71:597-622

Gurnett DA, Kurth WS, Kirchner DL, Hospodarsky GB, Averkamp TF, Zarka P, Lecacheux A, Manning R, Roux A, Canu P, Cornilleau-Wehrlin N, Galopeau P, Meyer A, Boström R, Gustafsson G, Wahlund J-E, Âhlen L, Rucker HO, Ladreiter HP, Macher W, Woolliscroft LC, Alleyne H, Kaiser ML, Desch MD, Farrell WM, Harvey CC, Louarn P, Kellogg PJ, Goetz K, Pedersen A (2004) The Cassini radio and plasma wave investigation. Space Sci Rev 114:395-463

Holback B, Jansson S-E, Åhlén L, Lundgren G, Lyngdal L, Powell S, Meyer A (1994) The Freja wave and plasma density experiment. Space Sci Rev 70:577-592

Horne RB, Thorne RM (2003) Relativistic electron acceleration and precipitation during resonant interactions with whistler-mode chorus. Geophys Res Lett 30:1527. https://doi.org/10.1029/2003GL016973

Horne RB, Thorne RM, Glauert SA, Meredith NP, Pokhotelov D, Santolík O (2007) Electron acceleration in the Van Allen radiation belts by fast magnetosonic waves. Geophys Res Lett 34:L17107. https://doi. org/10.1029/2007GL030267

Hudson MK, Elkington SR, Lyon JG, Goodrich CC (2000) Increase in relativistic electron flux in the inner magnetosphere: ULF wave mode structure. Adv Space Res 25:2327-2337

Jacobs JA, Kato Y, Matsushita S, Troitskaya VA (1964) Classification of geomagnetic micropulsations. J Geophys Res 69:180-181. https://doi. org/10.1029/JZ069i001p00180

Jordanova VK, Albert J, Miyoshi Y (2008) Relativistic electron precipitation by EMIC waves from self-consistent global simulations. J Geophys Res 113:A00A10. https://doi.org/10.1029/2008JA013239

Kasaba Y, Bougeret J-L, Blomberg LG, Kojima H, Yagitani S, Moncuquet M, Trotignon J-G, Chanteur G, Kumamoto A, Kasahara Y, Lichtenberger J, Omura Y, Ishisaka K, Matsumoto H (2010) The plasma wave investigation (PWI) onboard the BepiColombo/MMO: first measurement of electric fields, electromagnetic waves, and radio waves around Mercury. Planet Space Sci 58:238-278

Kasahara Y, Miyoshi Y, Omura Y, Verkhoglyadova OP, Nagano I, Kimura I, Tsurutani BT (2009) Simultaneous satellite observations of VLF chorus, hot and relativistic electrons in a magnetic storm "recovery" phase. Geophys Res Lett 36:L01 106. https://doi.org/10.1029/2008GL036454

Kasahara Y, Kasaba Y, Kojima H, Yagitani S, Ishisaka K, Kumamoto A, Tsuchiya F, Ozaki M, Matsuda S, Imachi T, Miyoshi Y, Hikishima M, Katoh Y, Ota M, Shoji M, Matsuoka A, Shinohara I (2018) The Plasma Wave Experiment (PWE) on board the Arase (ERG) satellite. Earth Planets Space. https://doi. org/10.1186/s40623-018-0842-4

Katoh Y, Omura Y (2007) Relativistic particle acceleration in the process of whistler-mode chorus wave generation. Geophys Res Lett 34:L13102. https://doi.org/10.1029/2007GL029758

Katoh Y, Kojima H, Hikishima M, Takashima T, Asamura K, Miyoshi Y, Kasahara Y, Kasahara S, Mitani T, Higashio N, Matsuoka A, Ozaki M, Yagitani S, Yokota S, Matsuda S, Kitahara M, Shinohara I (2018) Software-type Wave-Particle Interaction Analyzer on board the Arase satellite. Earth Planets Space 70:4. https://doi.org/10.1186/s40623-017-0771-7

Kletzing CA, Kurth WS, Acuna M, MacDowall RJ, Torbert RB, Averkamp T, Bodet D, Bounds SR, Chutter M, Connerney J, Crawford D, Dolan JS, Dvorsky R, Hospodarsky GB, Howard J, Jordanova V, Johnson RA, Kirchner DL, Mokrzycki B, Needell G, Odom J, Mark D, Pfaff R Jr, Phillips JR, Piker CW, Remington SL, Rowland D, Santolik O, Schnurr R, Sheppard D, Smith CW, Thorne RM, Tyler J (2013) The electric and magnetic field instrument suite and integrated science (EMFISIS) on RBSP. Space Sci Rev 179:127-181

Kumamoto A, Tsuchiya F, Kasahara Y, Kasaba Y, Kojima H, Yagitani S, Ishisaka K, Imachi T, Ozaki M, Matsuda S, Shoji M, Matsuoka A, Katoh Y, Miyoshi Y, Obara T (2018) High Frequency Analyzer (HFA) of Plasma Wave Experiment (PWE) onboard the Arase spacecraft. Earth Planets Space. https:// doi.org/10.1186/s40623-018-0854-0

Le Contel O, Leroy P, Roux A, Coillot C, Alison D, Bouabdellah A, Mirioni L, Meslier L, Galic A, Vassal MC, Torbert RB, Needell J, Rau D, Dors I, Ergun RE, Westfall J, Summers D, Wallace J, Magnes W, Valavanoglou A, Olsson G, Chutter M, Macri J, Myers S, Turco S, Nolin J, Bodet D, Rowe K, Tanguy M, de la Porte B (2016) The search-coil magnetometer for MMS. Space Sci Rev 199:257-282
Lefeuvre F, Parrot M, Rauch JL, Poirier B, Masson A, Mogilevsky M (1998) Preliminary results from the MEMO multicomponent measurements of waves on-board INTERBALL 2. Ann Geophys 16:1117-1136

Matsuda S, Kasahara Y, Kojima H, Kasaba Y, Yagitani S, Ozaki M, Imachi T, Ishisaka K, Kumamoto A, Tsuchiya F, Ota M, Kurita S, Miyoshi Y, Hikishima M, Matsuoka A, Shinohara I (2018) Onboard software of Plasma Wave Experiment aboard Arase: instrument management and signal processing of WaveForm Capture/Onboard Frequency Analyzer. Earth Planets Space. https://doi.org/10.1186/s40623-018-0838-0

Matsumoto H, Nagano I, Anderson RR, Kojima H, Hashimoto K, Tsutsui M, Okada T, Kimura I, Omura Y, Okada M (1994) Plasma wave observations with GEOTAIL spacecraft. J Geomagn Geoelectr 46:59-95

Matsuoka A, Teramoto M, Nomura R, Nose M, Fujimoto A, Tanaka Y, Shinohara M, Nagatsuma T, Shiokawa K, Obana Y, Miyoshi Y, Mita M, Takashima T, Shinohara I (2018) The ARASE (ERG) magnetic field investigation. Earth Planets Space 70:43. https://doi.org/10.1186/s40623-018-0800-1

Miyoshi Y, Kataoka R (2005) Ring current ions and radiation belt electrons during geomagnetic storms driven by coronal mass ejections and corotating interaction regions. Geophys Res Lett 32:L21105. https://doi. org/10.1029/2005GL024590

Miyoshi Y, Sakaguchi K, Shiokawa K, Evans D, Albert J, Connors M, Jordanova V (2008) Precipitation of radiation belt electrons by EMIC waves, observed from ground and space. Geophys Res Lett 35:L23101. https://doi. org/10.1029/2008GL035727

Miyoshi Y, Ono T, Takashima T, Asamura K, Hirahara M, Kasaba Y, Matsuoka A, Kojima H, Shiokawa K, Seki K, Fujimoto M, Nagatsuma T, Cheng CZ, Kazama Y, Kasahara S, Mitani T, Matsumoto H, Higashio N, Kumamoto A, Yagitani S, Kasahara Y, Ishisaka K, Blomberg L, Fujimoto A, Katoh Y, Ebihara Y, Omura Y, Nosé M, Hori T, Miyashita Y, Tanaka Y-M, Segawa TT (2012) The Energization and Radiation in Geospace (ERG) Project. In: Summers D, Mann IR, Baker DN, Schulz M (eds) Dynamics of the Earth's radiation belts and inner magnetosphere. American Geophysical Union, Washington. https://doi.org/10.1029/2012GM001304

Nagano I, Yagitani S, Kojima H, Matsumoto H (1996) Analysis of wave normal and poynting vectors of the chorus emissions observed by GEOTAIL. J Geomagn Geoelectr 48:299-307

Nishimura Y, Bortnik J, Li W, Thorne RM, Lyons LR, Angelopoulos V, Mende SB, Bonnell JW, Le Contel O, Cully C, Ergun R, Auster U (2010) Identifying the driver of pulsating aurora. Science 330:81-84. https://doi.org/10.1126/ science.1193186

Omura Y, Zhao Q (2012) Nonlinear pitch angle scattering of relativistic electrons by EMIC waves in the inner magnetosphere. J Geophys Res 117:A08227. https://doi.org/10.1029/2012JA017943

Ozaki M, Yagitani S, Takahashi K, Nagano I (2013) Dual-resonant search coil for natural electromagnetic waves in the near-Earth environment. IEEE Sens J 13:644-650

Ozaki M, Yagitani S, Kojima H, Takahashi K, Kitagawa A (2014) Current-sensitive CMOS preamplifier for investigating space plasma waves by magnetic search coils. IEEE Sens J 14:421-429

Ozaki M, Yagitani S, Takahashi K, Imacih T, Koji H, Higashi R (2015) Equivalent circuit model for the electric field sensitivity of a magnetic search coil of space plasma. IEEE Sens J 15:1680-1689

Ozaki M, Yagitani S, Kojima H, Takahashi K, Koji H, Zushi T, Tokunaga Y (2016) Development of an ASIC preamplifier for electromagnetic sensor probes for monitoring space electromagnetic environments. Earth Planets Space 68:91. https://doi.org/10.1186/s40623-016-0470-9

Pickett JS, Grison B, Omura Y, Engebretson MJ, Dandouras I, Masson A, Adrian ML, Santolík O, Décréau PME, Cornilleau-Wehrlin N, Constantinescu D (2010) Cluster observations of EMIC triggered emissions in association with Pc1 waves near Earth's plasmapause. Geophys Res Lett 37:L09104. https://doi.org/10.1029/2010GL042648

Reeves GD, McAdams KL, Friedel RHW, O'Brien TP (2003) Acceleration and loss of relativistic electrons during geomagnetic storms. Geophys Res Lett 30:1529. https://doi.org/10.1029/2002GL016513

Reeves GD, Spence HE, Henderson MG, Morley SK, Friedel RHW, Funsten HO, Baker DN, Kanekal SG, Blake JB, Fennell JF, Claudepierre SG, Thorne RM, Turner DL, Kletzing CA, Kurth WS, Larsen BA, Niehof JT (2013) Electron acceleration in the heart of the Van Allen radiation belts. Science 341:991-994. https://doi.org/10.1126/science.1237743 
Rhouni A, Sou G, Leroy P, Coillot C (2013) Very low 1/f noise and radiationhardened CMOS preamplifier for high-sensitivity search coil magnetometers. IEEE Sens J 13:159-166

Robert P, Cornilleau-Wehrlin N, Piberne R, de Conchy Y, Lacombe C, Bouzid V, Grison B, Alison D, Canu P (2014) CLUSTER-STAFF search coil magnetometer calibration - comparisons with FGM. Geosci Instrum Methods Data Syst 3:153-177

Rodger CJ, Raita T, Clilverd MA, Seppälä A, Dietrich S, Thomson NR, Ulich T (2008) Observations of relativistic electron precipitation from the radiation belts driven by EMIC waves. Geophys Res Lett 35:L16106. https://doi. org/10.1029/2008GL034804

Roux A, Le Contel O, Coillot C, Bouabdellah A, de la Porte B, Alison D, Ruocco S, Vassal MC (2008) The search coil magnetometer for THEMIS. Space Sci Rev 141:265-275

Experimenters S (1979) Measurements of electric and magnetic wave fields and of cold plasma parameters on-board GEOS-1. Preliminary results. Planet Space Sci 27:317-339

Santolík O, Gurnett DA, Pickett JS, Parrot M, Cornilleau-Wehrlin N (2003) Spatio-temporal structure of storm-time chorus. J Geophys Res 108:1278. https://doi.org/10.1029/2002JA009791

Scarf FL, Fredricks RW, Gurnett DA, Smith EJ (1978) The ISEE-C plasma wave investigation. IEEE Trans Geosci Electron 16:191-195

Schulz M, Lanzerotti $\sqcup$ (1974) Particle diffusion in the radiation belts. Springer, New York

Séran HC, Fergeau P (2005) An optimized low-frequency three-axis search coil magnetometer for space research. Rev Sci Instrum 76:044502. https://doi. org/10.1063/1.1884026

Shawhan SD, Gurnett DA, Odem DL, Helliwell RA, Park CG (1981) The plasma wave and quasi-static electric field instrument (PWI) for Dynamics Explorer-A. Space Sci Intrum 5:535-550

Shiokawa K et al (2017) Ground-based instruments of the PWING project to investigate dynamics of the inner magnetosphere at subauroral latitudes as a part of the ERG-ground coordinated observation network. Earth Planets Space 69:160. https://doi.org/10.1186/s40623-017-0745-9

Shprits YY, Elkington SR, Meredith NP, Subbotin DA (2008) Review of modeling of losses and sources of relativistic electrons in the outer radiation belt I: radial transport. J Atmos Sol Terr Phys 70:1679-1693

Shprits YY, Subbotin D, Drozdov A, Usanova ME, Kellerman A, Orlova K, Baker DN, Turner DL, Kim KC (2013) Unusual stable trapping of the ultrarelativistic electrons in the Van Allen radiation belts. Nat Phys 9:699-703. https:// doi.org/10.1038/nphys2760

Summers D, Thorne RM, Xiao F (1998) Relativistic theory of wave-particle resonant diffusion with application to electron acceleration in the magnetosphere. J Geophys Res 103:20487-20500. https://doi. org/10.1029/98JA01740

Summers D, Ni B, Meredith NP, Horne RB, Thorne RM, Moldwin MB, Anderson RR (2008) Electron scattering by whistler-mode ELF hiss in plasmaspheric plumes. J Geophys Res 113:A04219. https://doi. org/10.1029/2007JA012678

Thorne RM (2010) Radiation belt dynamics: the importance of waveparticle interactions. Geophys Res Lett 37:L22107. https://doi. org/10.1029/2010GL044990

Thorne RM, Li W, Ni B, Ma Q, Bortnik J, Chen L, Baker DN, Spence HE, Reeves GD, Henderson MG, Kletzing CA, Kurth WS, Hospodarsky GB, Blake JB, Fennell JF, Claudepierre SG, Kanekal SG (2013) Rapid local acceleration of relativistic radiation-belt electrons by magnetospheric chorus. Nature 504:411-414. https://doi.org/10.1038/nature12889

Tsurutani BT, Smith EJ (1974) Postmidnight chorus: a substorm phenomenon. J Geophys Res 79:118-127. https://doi.org/10.1029/JA079i001p00118

Yagitani S, Habagishi T, Omura Y (2014) Geotail observation of upper band and lower band chorus elements in the outer magnetosphere. J Geophys Res Space Phys 119:4694-4705. https://doi.org/10.1002/2013JA019678

\section{Submit your manuscript to a SpringerOpen ${ }^{\odot}$ journal and benefit from:}

- Convenient online submission

- Rigorous peer review

- Open access: articles freely available online

- High visibility within the field

- Retaining the copyright to your article

Submit your next manuscript at springeropen.com 